\title{
Stent migration requiring surgical removal: a serious adverse event after bariatric megastent placement
}

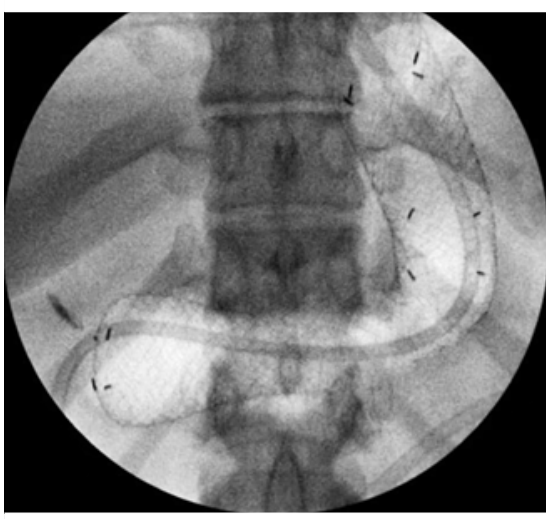

- Fig. 1 Radiographic image showing the final position of the first megastent placed to treat a leak at the angle of His following sleeve gastrectomy.

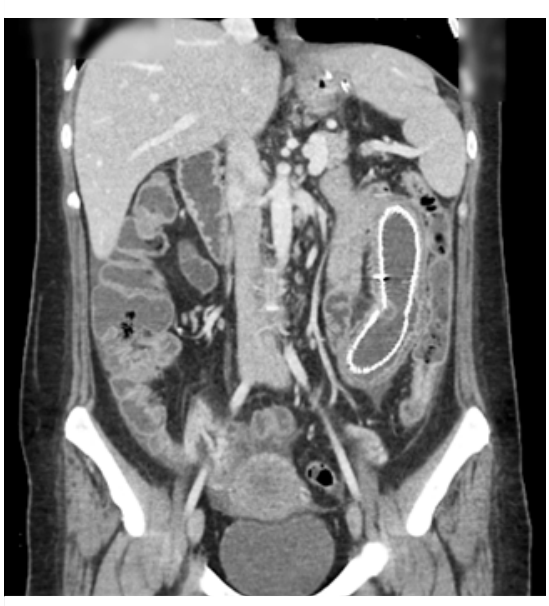

> Fig. 4 Computed tomography scan showing the megastent located in the proximal jejunum.

Leaks are serious complications after sleeve gastrectomy, with an incidence rate up to $7 \%$ [1]. Currently, stent placement and other endoscopic techniques are recommended for the treatment of post-bariatric leaks (PBLs) [2]. Bariatric stents are a feasible, effective and lifesaving method [3]. They achieve leak closure rates between $72.8 \%$ and $87.8 \%$ but are associated with significant migration rates $(16.9 \%-28.2 \%)[1,4]$. The large bariatric-specific stent (LBSS) has

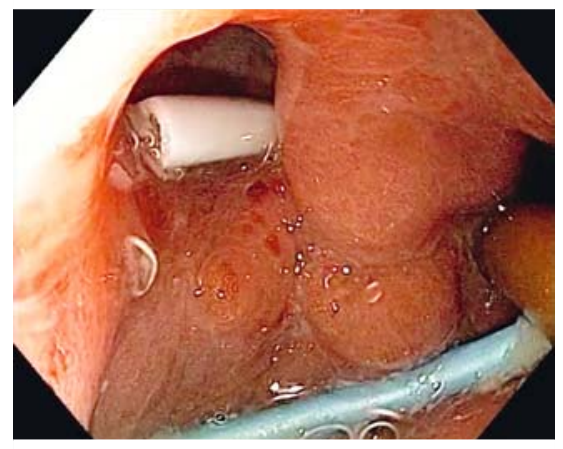

- Fig. 2 Endoscopic image showing the two pigtail stents placed at the site of the leak.

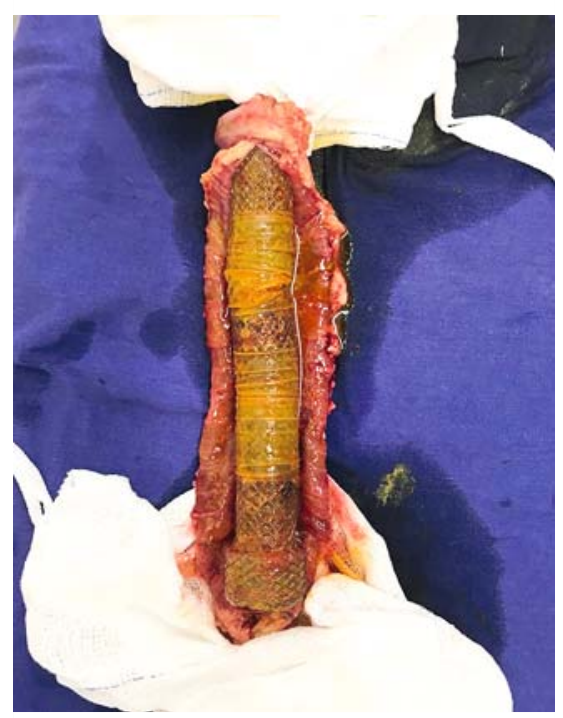

- Fig. 5 Macroscopic appearance of the 27-cm enterectomy specimen.

been developed as an important device to fit bariatric anatomy and avoid migration because of its long length with the distal edge being placed in the duodenum [5].

We report the case of 34-year-old woman who underwent sleeve gastrectomy. On the 5th post-operative day (POD), she developed abdominal pain and purulent output from the drain. Computed tomog-

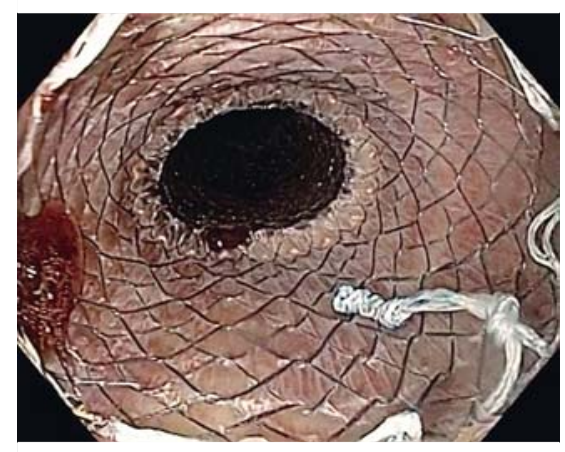

- Fig. 3 Endoscopic image showing the second megastent in position.

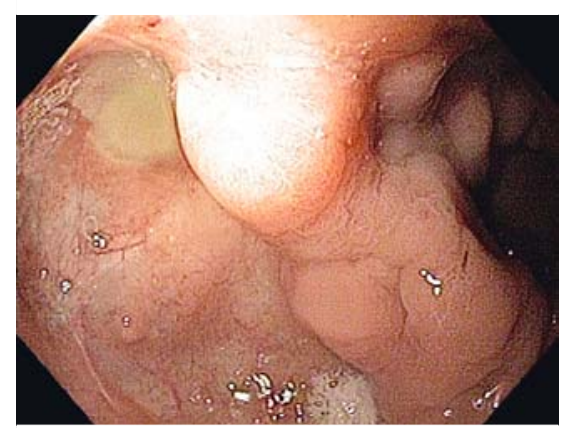

- Fig. 6 Endoscopic image showing a shallow ulcer at the angle of His after closure of the leak.

raphy $(C T)$ scanning showed a leak at the angle of His without any collections.

We opted to place an LBSS $(24 \mathrm{~cm} \times$ $28 \mathrm{~mm}$; Hanarostent, MITECH) to bypass the whole stomach ( $\triangleright$ Fig. 1 ). The LBSS was removed 4 weeks later (33th POD), but the leak persisted. We then placed two single-pigtail stents ( $>$ Fig. 2 ) and kept them in place for 10 days, but this was also unsuccessful. On the 43 rd POD, we removed the pigtail stents, performed a septotomy, and placed a second LBSS (> Fig.3).

After 3 weeks (64th POD), the patient again presented with abdominal pain. On this occasion, esophagogastroduo- 


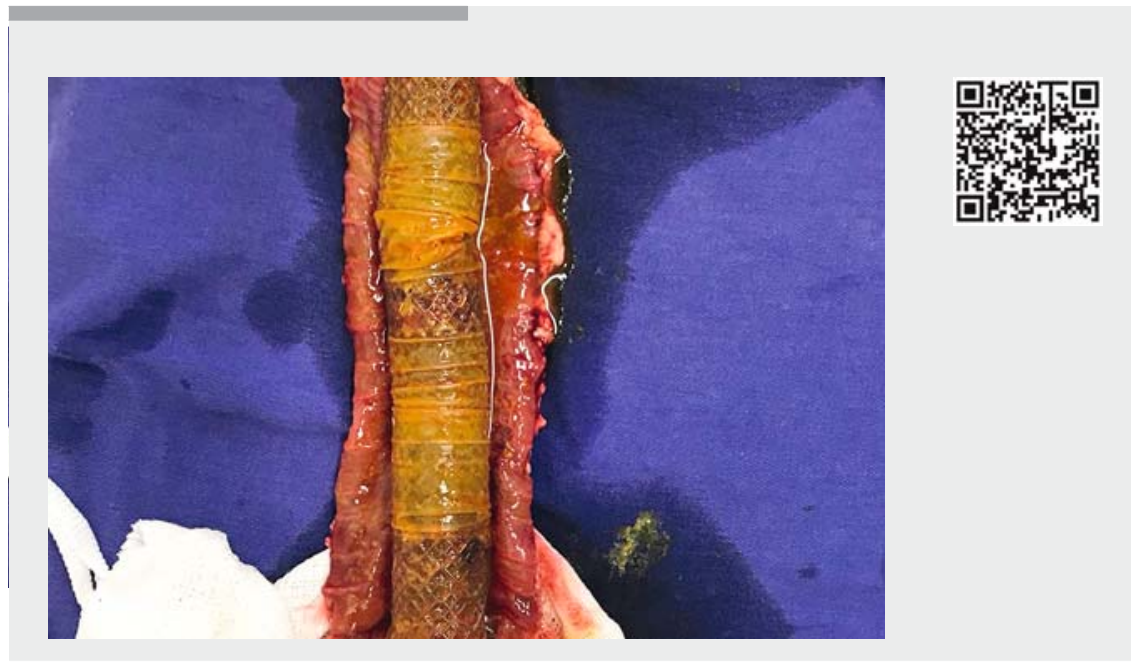

$\checkmark$ Video 1 Insertion of the first bariatric megastent to treat a leak; removal of the megastent and insertion of two single-pigtail stents; removal of pigtail stents and insertion of a second megastent; the bariatric megastent is found to have migrated into the small bowel and eventually required surgical removal. denoscopy (EGD) and upper gastrointestinal series showed complete closure of the leak, but the LBSS could not be seen. ACT scan identified the stent in the proximal jejunum (> Fig.4). An enteroscopic attempt to retrieve the stent and 7 days of conservative treatment (laxative, diet, and antispasmodic drug) were unsuccessful, and a laparoscopic enterectomy and primary anastomosis were eventually needed ( $>$ Fig.5). Finally, 15 days later (86th POD), she was asymptomatic and an EGD showed only a shallow ulcer at the angle of His ( $>$ Fig. 6; $>$ Video 1).

An LBSS seems to be a useful device for PBL management, but it may cause serious adverse events. Further controlled studies should assess the precise success and complication rates of such stent.

Endoscopy_UCTN_Code_CPL_1AH_2AK

Competing interests
The authors

Antonio C. Madruga Neto ${ }^{1}$, Vitor O. Brunaldi ${ }^{1}$, Ossamu Okazaki ${ }^{1}$, Marco A. Santo Filho², Antônio A. Miranda Neto², Vera L. Anapaz ${ }^{3}$, Eduardo G. H. de Moura

1 Gastrointestinal Endoscopy Unit, Hospital das Clínicas, University of São Paulo Medical School, São Paulo, Brazil

2 Bariatric and Metabolic Surgery Unit, Hospital das Clínicas, University of São Paulo Medical School, São Paulo, Brazil

3 Gastroenterology Department, Hospital Professor Doutor Fernando Fonseca, Lisboa, Portugal

\section{Corresponding author}

\section{Antonio Coutinho Madruga Neto, MD} Hospital das Clínicas, University of São Paulo Medical School, Dr. Arnaldo Av, 455, 01246-903, São Paulo, Brazil antonio_coutinho_neto@hotmail.com antonio.cmneto@hc.fm.usp.br
[1] Okazaki O, Bernardo WM, Brunaldi VO et al. Efficacy and safety of stents in the treatment of fistula after bariatric surgery: a systematic review and meta-analysis. Obes Surg 2018; 28: 1788 - 1796

[2] Kim J, Azagury D, Eisenberg D et al. ASMBS position statement on prevention, detection, and treatment of gastrointestinal leak after gastric bypass and sleeve gastrectomy, including the roles of imaging, surgical exploration, and nonoperative management. Surg Obes Relat Dis 2015; 11: 739-748

[3] de Moura EG, Galvão-Neto MP, Ramos AC et al. Extreme bariatric endoscopy: stenting to reconnect the pouch to the gastrojejunostomy after a Roux-en-Y gastric bypass. Surg Endosc 2012; 26: $1481-1484$

[4] Puli SR, Spofford IS, Thompson CC. Use of self-expandable stents in the treatment of bariatric surgery leaks: a systematic review and meta-analysis. Gastrointest Endosc 2012; 75: 287-293

[5] Shehab H, Abdallah E, Gawdat K et al. Large bariatric-specific stents and over-the-scope clips in the management of post-bariatric surgery leaks. Obes Surg 2018; 28: 15-24

\section{Bibliography}

DOI https://doi.org/10.1055/a-0725-7718

Published online: 17.10.2018

Endoscopy 2018; 50: E344-E345

(c) Georg Thieme Verlag KG

Stuttgart · New York

ISSN 0013-726X

\section{ENDOSCOPY E-VIDEOS \\ https://eref.thieme.de/e-videos}

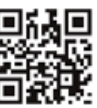

Endoscopy E-Videos is a free access online section, reporting on interesting cases and new techniques in gastroenterological endoscopy. All papers include a high quality video and all contributions are freely accessible online.

This section has its own submission website at https://mc.manuscriptcentral.com/e-videos 